\title{
A Comparison on the Effect of Doing Exercise, Listening to Music and Taking Quiet Rest on Mood Changes 比較進行運動、聽音樂及靜坐對情緒的影響
}

\author{
Eric C.K. TSANG \\ Department of Health and Physical Education, \\ The Hong Kong Institute of Education, HONG KONG
}

曾卓權

香港教育學院健康與體育學系

\begin{abstract}
This study compared the effect of doing exercise, listening to music and taking quiet rest on mood changes. Three hundred and thirty seven secondary school students participated in this study. They were randomly assigned to three groups: (a) aerobic exercise group; (b) light instrumental music group; and (c) quiet rest group. All participants were administered with the Profile Of Mood State (POMS; Grove \& Prapavessis, 1992) before and after the thirty minutes activity. It was found that both doing exercise and listening to music were effective in resulting a mood change by lowering the negative mood state. Participants after doing exercise reported a significant increase in positive mood. Conversely, participants after taking a quiet rest reported an increase in negative mood. It was concluded that doing exercise was most effective to achieve a positive mood change, yet, for those non-exercisers, listening to music could also induce positive psychological changes.
\end{abstract}

\section{摘 要}

此研究是比較進行運動, 聆聽音樂, 及靜坐, 對情緒的影響。三百三十七位参與測試的中學生, 隨機分為三組, (a) 帶氧運 動組, (b) 聆聽輕音樂組, 及 (c) 靜坐組。實驗進行三十分鐘, 各参加者在實驗前及後都以Profile Of Mood State (POMS; Grove \& Prapavessis, 1992) 作答, 以探討他們的情緒變化; 研究顯示進行運動及聆聽音樂, 都能有效降低負面情緒, 而進行運 動者在正面情緒方面, 更有明顯提升; 反而, 靜坐組顯示在實驗後負面情緒有明顯上升, 此研究作出結論, 進行運動對改善情緒 最為有效, 但聆聽音樂對非運動愛好者, 亦能改善心理狀况。

\section{Introduction}

Emotional stability of young people is a growing concern for school educators. According to a study conducted by the Centre for Health Education and Health Promotion of the Chinese University of Hong Kong (2003) with over three thousand secondary students showed that $29.2 \%$ of the students had a feeling of depression and hopelessness in two consecutive weeks in the past twelve months and $11.4 \%$ of them considered their emotional problem influenced their daily life and social activities. The source of these emotional problems came mostly from the pressure of their studies and examinations. Consequently, there was a great need for schools in Hong Kong to provide a more supportive and positive environment creating strong psychosocial correlation with health compromising behaviors for children. Schools should have the responsibility to provide an important avenue for health education and health promotion programs that aim to enhance a positive mood state.

Physical activity and exercise have a positive impact on many aspects of health. Regular exercise decreases risk for several diseases, including coronary heart disease, 
hypertension, diabetes, certain types of cancer, obesity and osteoporosis (Kesaniemi, Danforth, Jensen, Kopelman, Lefebvre, \& Reeder, 2001). Besides improving health, research over the last ten years substantiated that physical activity also improves psychological well-being (Dubbert, 2002), such as reducing anxiety and depression (Lane, Crone-Grant, \& Lane, 2002). Exercise also had a positive influence on improving self-esteem (McAuley, Blissmer, Katula, Duncan, \& Mihalko, 2000), and had been widely used as a treatment for depression and anxiety (Salmon, 2001; Mather, Rodriguez, Guthrie, McHarg, Reid, \& McMurdo, 2002). Studies in exercise psychology have strong support that mood enhancement is a primary benefit of physical activity (Berger, 1996; Morgan, 1997). The International Society for Sport Psychology (1992) also described the psychological benefits of physical activity and concluded that exercise has been related to desirable changes in mood. Apart from doing exercise, many researchers reported that music could also be used as a tool to improve the mood state (Dibben, 2004; Murrock, 2005). Musical compositions could play a significant role in human physiological and psychological functions, thus creating alterations in mood. Bahrke, \& Morgan (1978) examined the influence of acute physical activity and meditation on state anxiety. The results of the study suggested that acute physical activity, mediation, and a quiet rest session were equally effective in reducing state anxiety. Raglin, \& Morgan (1987) also found that quiet rest was also said to be a good way in reducing anxiety and depression and causes an improvement in the mood state.

Previous studies showed that doing exercise, listening to music and quiet rest were some of the ways to help the students to reduce their anxiety, depression and negative feelings. Hence, the purpose of this study was to find out whether these three kinds of activities could effectively improve mood states, and, through comparison, to find out which method was more effective and suitable for secondary school students.

\section{Effect of Exercise on Mood Change}

Several studies (Roth, 1989; Roth, Bachtler, \& Fillingim, 1990; Scully, Kremer, Meade, Graham, \& Dudgeon, 1998) indicated that a single session of exercise could result in reasonably large mood benefits by increasing the positive mood states, such as positive well-being, vigor, elation, peaceful, calm and relax; also, decreasing the negative mood states such as psychological distress, tension, anxiety, confusion and anger (Hassmen, Koivula, \& Uutela, 2000). The studies by Kravitz (2000) and Dunn, Trivedi, Kampert, Clark, \& Chambliss (2002) found that exercise was the most important element in the comprehensive treatment programs for depression. Peluso, \& Andrade (2005) also found that physical activity was an important public health tool used in the treatment and prevention of various physical diseases, as well as in the treatment of some psychiatric diseases such as depressive and anxiety disorders. Physical activity could also be associated with impaired mental health. Besides, McAuley, et al. (2000) indicated that exercise could also have a positive influence on improving self-esteem.

Studies were also conducted to find out the mode of exercise that would affect the mood changes. Yueng (1996), in his review, found that the majority of work on the exercise-mood relationship supported that cardiovascular exercise leads to mood improvement. Some of the studies (Brosse, Sheets, Lett, \& Blumenthal, 2002; Fox, 1999; Kravitz, 2000; Lane \& Lovejoy, 2001) found that short bursts of five minutes of exercise would stimulate antianxiety effects. They concluded that both aerobic and anaerobic exercises seemed to be equally effective in producing anti-depressive effects and could positively affect different mood states including tension, fatigue, anger and vigor. However, many studies (Ekkekakis, Hall, VanLanduyt, \& Petruzzello, 2000; Hassmen, Koivula \& Uutela, 2000; Kravitz, 2000; McAuley, et al., 2000; Scully, et al., 1998) indicated that aerobic exercise might have a more pronounced effect than anaerobic exercise. Aerobic exercise was more beneficial for the reduction of anxiety and stress. In addition, aerobic exercise was easier to be controlled, thus, aerobic exercise was used in this study.

The duration of exercise has also been studied quite extensively. Ekkekakis, et al. (2000) suggested that a ten to fifteen minute walk could result in mood improvements. Berger \& Motl (2000) recommended that the duration of an exercise session for changes in mood to occur was approximately 20-30 minutes, and positive mood changes might occur at that time.

Concerning the intensity of exercise, Zervas, Ekkekakis, Emmanuel, Psychoudaki, \& Kakkos (1993) had observed a moderate level of exertion led to more mood change than either a low or high exertion. Tate \& 
Petruzzello (1995) examined the effect of varying levels of exercise intensity on the state anxiety, positive affect, and negative affect. The finding of the study suggested that aerobic exercise performed at $55-70 \%$ of $\mathrm{VO} 2 \mathrm{max}$ produced not only a decrease in negative feeling states, but also increased in positive affect. Motl, Berger, \& Wilson (1996) examined the mood changes associated with exercise in cyclists, and found that participants reported more consistent mood benefits after the moderate intensity exercise. Low intensity activities had been reported that improvements were less consistent, however, high intensity exercise also led to deterioration in mood in some studies. Berger (1996) and Berger \& Motl (2000) agreed that moderate intensity activity was the best way for improving mood. Moderate - intensity exercise had been defined by the American College of Sports Medicine (2006) as $64-76 \%$ of maximum heart rate.

\section{Effect of Music on Mood Change}

Murrock (2005) found out that musical compositions played a significant role in human physiological and psychological functions, thus creating alterations in mood. Music produced psychological effects by engaging the limbic system, which was the center of emotions, sensations, and feelings. Through the limbic system, music had the ability to bring about a broad range of emotional states. Music enhanced mood during physical activity by increasing enjoyment and might stimulate continued performance. Music could also act as a distracter when activities were not as pleasurable. Thus, the powerful effect of music was located in its capacity to alter moods, communicate feelings, and create distraction.

Siu (1981) found out that music could calm down one's emotion, increase concentration and develop potentiality. Music was particularly effective on reducing people's anxiety and pressure, keeping calm and relaxed. Music could also act as an aid on some treatments. Different kinds of music would have different effects on people, however, in general, the more effective kind of music should be simple in composition and texture and using fewer musical instruments. Music being chosen should be more stable and without any extraordinary high pitch. It was better to have music performed with musical instruments only and without any vocals. In the study by DiGiacomo, \& Kirby (2006), the results also indicated that emotional responses were affected by musical mode. The major mode condition elicited a positive response, the minor mode condition elicited a negative response, and the mixed mode condition elicited a moderate combination of emotional responses.

Consequently, the music used in this study was some kind of light music in major mode, simple in composition, using only few musical instruments and without any vocals.

\section{Effect of Quiet Rest on Mood Change}

Bahrke, \& Morgan (1978) examined the influence of acute physical activity and meditation on state anxiety. The results of the study suggested that acute physical activity, mediation, and a quiet rest session were equally effective in reducing state anxiety. Raglin, \& Morgan (1987) examined the influence of exercise and quiet rest on state anxiety and blood pressure. They concluded that both exercise and quiet rest had similar effects on state anxiety.

So during the test in quiet rest, the participants were arranged to just sit and rest inside a quiet and comfortable place and without doing anything.

\section{Method}

\section{Participants}

A total of 337 secondary students from Buddhist Hung Sean Chau Memorial College took part in the study. They came from different classes between secondary 1 to secondary 6 with age ranging from 12 years to 20 years $($ mean $=14.95$ years; S.D. $=2.07)$. Among them, 181 were males and 156 were females.

\section{Instrument}

Mood state was measured before and after each exercise test session with the self-report Profile of Mood States (POMS) inventory originally developed by McNair, Lorr, \& Droppleman (1971). Participants were referred to their feelings at that moment. The POMS is one the most frequently used measures in assessing exercise and mood states. The POMS Standard Form contains 65 items rated on a 5-point scale. Grove \& Prapavessis (1992) revised the original questionnaire and reduced to 40 adjectives that measured tension, depression, fatigue, vigor, confusion, anger, and esteem-related affect. Total mood is measured by subtracting the vigor-activity subscale 
score from the sum of the remaining subscale scores. Reliability coefficients for the subscales ranged from .66 to .95 with a mean of .80 . This modified form of the shortened version of POMS has shown to have acceptable psychometric properties for use in sport settings, and that it may be particularly useful for researchers when economy of assessment is important.

\section{Procedures}

Consent letters were obtained from the participants and their parents before the start of the study. Participants were divided into three groups, Group A, B and C. Group A participants had to do exercise in the school fitness room. Group B participants had to listen to music at the student activity center. While Group C participants had quiet rest in the school hall. Before doing the test, all the participants had to answer the POMS questionnaires. Participants were asked to complete the questionnaires according to their feelings at that moment which took about five minutes. After they had finished the questionnaires, the tests began. The participants in Group A were asked to do aerobic exercise in the school fitness room. They had to exercise for 30 minutes in a moderate intensity [about $64-76 \%$ of their maximum heart rate or at level 3 (moderate) $\sim 4$ (somewhat hard) in the 10 point scale of the Perceived Exertion Rate]. The participants in Group B were asked to find a seat and listened to the light music. The participants of Group $\mathrm{C}$ were asked to find a comfortable place in the school hall, resting and sat quietly without doing anything. The tests lasted for 30 minutes. Then all the participants in the three different groups were asked to do the POMS questionnaires again. They had to complete the questionnaires according to their feelings at that moment which took about five minutes.

\section{Data Analysis}

The forty items from the questionnaires were reduced into seven subscales of anger, confusion, depression, esteem, fatigue, tension and vigor. Subscales of anger, confusion, depression, fatigue and tension were added up to form the Negative Mood State (NM); while the subscales of esteem and vigor were combined to form the Positive Mood State (PM). Total Mood Disturbance (TMD) was derived by subtracting Positive Mood State (PM) from Negative Mood State (NM). Mood Change (MC) denoted the difference between the Total Mood Disturbance After Experiment (ATMD) and Total Mood Disturbance Before Experiment (BTMD). The subscales of Negative Mood State (NM), Positive Mood State (PM), Total Mood Disturbance (TMD) and Mood Change (MC) were used for analysis in this study. Paired Sample T-tests were used to examine the mood change of participants before and after the experiment. Analysis of Variance (ANOVA) was used to verify whether there were significant differences between the three groups of participants in the mood change and followed by the Post-hoc test using Tukey HCD to locate the occurrence of differences.

\section{Results}

Table 1 provides information regarding the effects of different treatments on the mood subscales. There were significant decreases in negative mood states after exercise and music, but did not happen after taking quiet rest. The positive mood state had risen slightly after exercise but decreased significantly after taking quiet rest and listening to music. The total mood disturbances decreased significantly after exercise and music but, on the other hand, increased slightly after taking quiet rest. Consequently, there were positive mood changes after exercise and music but negative mood change after taking quiet rest.

Table 1. Effect of Different Treatments on Mood Changes.

\begin{tabular}{|l|l|l|l|l|l|l|}
\hline & Exercise & \multicolumn{2}{l|}{ Rest } & Music & \multicolumn{2}{l|}{} \\
\hline & Before & After & Before & After & Before & After \\
\hline NM & 9.19 & $8.37^{*}$ & 9.31 & 9.68 & 9.48 & $7.85^{* *}$ \\
\hline PM & 4.52 & 4.68 & 4.56 & $3.83^{* *}$ & 4.23 & $3.92^{* *}$ \\
\hline TMD & 4.67 & $3.69^{*}$ & 4.75 & 5.86 & 5.06 & $3.93^{*}$ \\
\hline MC & 0.98 & -1.11 & 1.07 & \\
\hline
\end{tabular}

Note $* \mathrm{p}<.05, * * \mathrm{p}<.001$ 
Comparisons were made between different treatments on mood changes with analysis of variance (ANOVA) statistical testing procedure followed by Tukey HCD Posthoc analysis. Significant differences were observed in all major mood subscales after treatment; with quiet rest demonstrated significantly high in negative $\operatorname{mood}(\mathrm{NM})$, total mood disturbance (TMD) and mood change (MC) in comparison with exercise and music. Treatment after exercise demonstrated significantly high in positive mood state (PM) in comparison with treatments after music and quiet rest (Table 2).

Table 2. Comparison between Different Effects of Treatment on Mood Changes.

\begin{tabular}{|l|l|l|l|l|}
\hline & Exercise & Rest & Music & F-Ratio \\
\hline NM & 8.37 & 9.68 & 7.85 & $10.29^{* *}$ \\
\hline PM & 4.68 & 3.83 & 3.92 & $15.44^{* *}$ \\
\hline TMD & 3.69 & 5.86 & 3.93 & $14.07^{* *}$ \\
\hline MC & 0.98 & -1.11 & 1.07 & $13.12^{* *}$ \\
\hline
\end{tabular}

Note $* * \mathrm{p}<.001$

\section{Discussion}

The major purpose of this study was to compare the effect of doing exercise, listening to music and taking quiet rest on the mood changes. Results from the prepost exercise mood state comparison indicated that doing exercise and listening to music were both effective in eliciting a positive mood change. This kind of positive mood change was achieved by lowering the negative mood state after listening to music which was in accordance with the findings by Siu (1981) which suggested that music was effective in reducing people's anxiety and pressure, keeping calm and relaxed.

After doing exercise, students also achieved a positive mood change not only in lowering the negative mood state significantly, there was also a slight rise in the positive mood state. Students reported that the rise in positive mood state after doing exercise was mainly a result in having an energetic feeling (vigor). These findings were in line with the large body of literature that supports the position of exercise leads to improved psychological affect. Doing exercise can provide a sense of achievement. Mastering a new skill or being excelled at a learned skill makes people feel accomplished and may have positive effects on the mood. According to Morgan (1978), exercise reduces depression by temporarily distracting people from the everyday stresses of their lives. Also, the social interaction hypothesis (North et al., 1990) pointed out that people may also feel happier due to the social interaction with their peers during exercise. There are other physiological explanations including the endorphin, cortisol, monoamine, and thermogenic hypotheses (Berger \& Motl, 2000). Actually, there are many possible explanations for the reasons why exercise affects people's mood, making them feel happier in life, whether the effects are physiological, psychological or a combination of both.

However, taking quiet rest did not result to positive mood change which was in contrary to the distraction hypothesis as suggested by Morgan (1978). Students had a significant decrease in positive mood state and a slight increase in negative mood state which resulted to a heightened mood disturbance. This finding indicates that taking quiet rest does not effectively result to a positive mood change for young people. The students reflected that taking a quiet rest without doing anything was a waste of time and they did not feel refreshed after the break. Berger and Motl (2000) have also indicated that personal enjoyment of the activity is an important criterion for improvement in mood. The quiet rest distraction condition may not be enjoyable to participants but rather boring that could have induced negative mood in this study.

The analysis of variance (ANOVA) also supported that when comparing the three kinds of treatments, both doing exercise and listening to music were significantly effective in promoting a positive mood change. Doing exercise was most effective when taking into consideration that it could provide an energetic feeling. The tranquilizing effect of exercise has been confirmed in this study. 


\section{Conclusion}

From the results of this study and also from the findings of the previous studies, the benefits of physical activities and exercise on mood improvement are further supported. At present, in Hong Kong, only about 5\% of the total regular time-table hours have been allocated for physical education lessons. In view of this, schools should provide more chance for physical activities after school hours or during school holidays by providing more time, space and opportunities for the students to participate in doing exercise. Schools can extend the opening hours and allow the students to stay longer after school to enjoy their physical activities within the school premises. Other resources, such as past students and parents, can be mobilized in helping the school to organize activities and courses. Many of them are enthusiastic and experienced in sport coaching.

The benefits of exercise in improving health and fitness are not disputed. Still, the psychological benefits of music on mood change has also confirmed in this study. This finding is important in the sense that there is still a majority of students who are physically inactive and mentally not willing to engage in exercise. Listening to music is easily accessible and inexpensive leisure activity that can provide affective benefits comparable to that of exercise. Therefore, schools should provide more opportunities for students to listen to music such as broadcasting some light music during recess and lunch time in order to alter their mood states.

In this study, taking quiet rest did not result to a positive change in mood; conversely, it lowered the positive mood state. It seems that taking quiet rest does not necessarily beneficial to young people who are basically energetic and active when they perceive it as boring and a waste of time.

The current study compared the effect of three different treatments on mood change in a group of secondary students. Further studies are warranted in comparing different modes of exercise on the effect of mood change. In this study, aerobic exercise has been used. In a school setting, there are other popular activities like ball games or fitness training, the psychological benefits of these activities need further examined. Gender and age differences on the preference of activities are also areas to be explored. It seems that males and younger students favor doing exercise, while females and more matured students prefer taking quiet rest. These areas deserve further systematic research attention due to their practical importance in the area of leisure and health for young people.

\section{References}

Bahrke, M. S., \& Morgan, W. P. (1978). Anxiety reduction following exercise and meditation. Cognitive Therapy and Research, 2, 323-333.

Berger, B. G. (1996). Psychological benefits of an active lifestyle: What we know and what we need to know. American Academy of Kinesiology and Physical Education, 48, 330-353.

Berger, B. G., \& Motl, R. W. (2000). Exercise and mood: A selective review and synthesis of research employing the Profile of Mood States. Journal of Applied Sport Psychology, 12, 69-92.

Brosse, A.L., Sheets, E.S., Lett, H.S., \& Blumenthal, J.A. (2002). Exercise and the treatment of clinical depression in adults: recent findings and future directions. Sports Medicine, 32, 741-760.

Chinese University of Hong Kong (2004). Predict youth risk behaviour - way to develop healthy and harmony school life. Retrieved December 26, 2007, from the Chinese University of Hong Kong Web site: http://www.cuhk.edu.hk/ipro/pressrelease/040408e. htm

Dibben, N. (2004). The role of peripheral feedback in emotional experience with music. Music Perception, 22 (1), 79-115.

DiGiacomo, A., and Kirby, B. J. (2006). The effect of musical mode on emotional state. Canadian Journal of Music Therapy, 12 (1), 68-91.

Dubbert, P.M. (2002). Physical activity and exercise: recent advances and current challenges. Journal of Consulting Clinical Psychology, 70, 526-536. 
Dunn, A.L., Trivedi, M.H., Kampert, J.B., Clark, C.G., \& Chambliss, H.O. (2002). The DOSE study. A clinical trial to examine efficacy and dose response of exercise as treatment for depression. Controlled Clinical Trials, 23, 584-603.

Ekkekakis, P., Hall, E. E., VanLanduyt, L. M., \& Petruzzello, S. J. (2000). Walking in (affective) circles: Can short walks enhance affect? Journal of Behavioral Medicine, 23 (3), 245-275.

Fox, K.R. (1999). The influence of physical activity on mental well-being. Public Health Nutrition, 2, 411418.

Grove, J. R. \& Prapavessis, H. (1992). Preliminary evidence for the reliability and validity of an abbreviated profile of mood states. International Journal Sport Psychology, 23, 93-109.

Hassmen, P. Koivula, N., \& Uutela, A. (2000). Physical exercise and psychological well-being: a population study in Finland. Preventative Medicine, 30 (1), 1725.

International Society of Sport Psychology. (1992). Physical activity and psychological benefits: A position statement from the international society of sport psychology. Journal of Applied Sport Psychology, 4, 94-98.

Kesaniemi, Y. A., Danforth, E., Jensen, M.D., Kopelman, P.G., Lefebvre, P., \& Reeder, B.A. (2001). Dose-response issues concerning physical activity and health: an evidence-based symposium. Medicine \& Science in Sports \& Exercise, 33, 351-358.

Kravitz, L. (2000). Exercise and psychological health. IDEA Personal Trainer, 11 (10), 19-21.

Lane, A.M., Crone-Grant, D., \& Lane, H. (2002). Mood changes following exercise. Perceptual Motor Skills, 94, $732-734$.
Lane, A.M. \& Lovejoy, D.J. (2001). The effects of exercise on mood changes: the moderating effect of depressed mood. Journal of Sports Medicine and Physical Fitness, 41, 539-545.

Mather, A.S., Rodriguez, C., Guthrie, M.F., McHarg, A.M., Reid, I.C. and McMurdo, M.E.T. (2002). Effects of exercise on depressive symptoms in older adults with poorly responsive depressive disorder: randomised controlled trial. British Journal of Psychiatry, 180, 411-415.

McAuley, E., Blissmer, B., Katula, J., Duncan, T.E., \& Mihalko, S.L. (2000). Physical activity, selfesteem, and self-efficacy relationships in older adults: a randomized controlled trial. Annals of Behavioral Medicine, 22, 131-139.

McNair, D., Lorr, M, \& Droppleman, L. (1971). Manual for the Profile of Mood States. San Diego, CA: Educational and Industrial Testing Service.

Motl, R. W., Berger, B. G., \& Wilson, T. E. (1996). Exercise intensity and the acute mood states of cyclists. Journal of Sport and Exercise Psychology, 18, S59.

Morgan, W.P. (1978). The mind of the marathoner. Psychology Today, 38-49.

Morgan, W.P. (Ed.)(1997). Physical activity and mental health. Washington DC: Taylor \& Francis.

Murrock, C. J. (2005). Psychology of moods. Hauppauge, NY, US: Nova Science Publishers.

North, T.C., McCullagh, P., \& Tran, Z.V. (1990). Effect of exercise on depression. In K.B. Pandolf \& J.O. Holloszy (Eds.), Exercise and sport science review, 18, 379-415. Baltimore: William \& Wilkins.

Peluso, M. A. M., and Andrade, L. H. S. G. (2005) Physical activity and mental health: the association between exercise and mood. Clinics, 60 (1), 61-70. 
Raglin, J. S., \& Morgan, W. P. (1987). Influence of exercise and quiet rest on state anxiety and blood pressure. Medicine and Science in Sports and Exercise, 19, 456-463.

Roth, D. L., (1989) Acute emotional and psychophysiological effects of aerobic exercise. The Society for Psychophysiological Research Inc., 26 (5).

Roth, D. L., Bachtler, S. D., and Fillingim, R. B. (1990). Acute emotional and cardiovascular effects of stress mental work during aerobic exercise. The Society for Psychophysiological Research Inc., 27 (6).

Salmon, P. (2001). Effects of physical exercise on anxiety, depression, and sensitivity to stress: a unifying theory. Clinical Psychology Review, 21, 33-61.

Scully, D., Kremer, J., Meade, M.M., Graham, R., \& Dudgeon, K. (1998). Physical exercise and psychological well-being: a critical review. British Journal of Sports Medicine, 32, 111-120.

Tate, A. K., \& Petruzzello, S. J. (1995). Varying the intensity of acute exercise: Implications for changes in affect. The Journal of Sports Medicine and Physical Fitness, 35, 295-302.
Yueng, R.R. (1996). The acute effects of exercise on mood state. Journal of Psychosomatic Research, 40, 123-141.

Zervas, Y., Ekkekakis, P., Emmanuel, C., Psychoudaki, M. and Kakkos, V. (1993). The acute effects of increasing levels of aerobic exercise intensity on mood states. In: Serpa, S., Alves, J., Ferreira, V. and Paulo-Brito, A. (Eds.). Proceedings of the 8th World Congress of Sport Psychology. Lisbon, Portugal.

\section{蕭秀娟 (1981) : 《音樂與情緒管理課程設計》, 國立新竹師範 學院在職進修推廣部國民教育研究所碩士論文, 未出版。}

\section{Correspondence:}

\section{Dr. Eric C.K. TSANG}

Department of Health and Physical Education, The Hong Kong Institute of Education, Tai Po, New erritories,

Hong Kong.

Tel: (852) 29487861

E-mail: cktsang@ied.edu.hk 